\title{
Phagocytic activity of monocytes and neutrophils in patients with periodontitis, whether or not associated to type 2 diabetes
}

\author{
Priscilla F. Naiff' ${ }^{1}$ Selma A.S. Kuckelhaus², Shirley Couto³, Mariângela Oliveira³, Luander M. \\ Santiago ${ }^{4}$ Andrea C.G. Cascaes ${ }^{3}$, Larissa F. Silva ${ }^{4}$, Laudimar A. Oliveira ${ }^{5}$, Daniela C. Grisi', \\ Valéria M. Carneiro', Maria do Carmo M. Guimarães ${ }^{6}$ \\ 1. Ambulatório de Periodontia, Secretaria Estadual de Saúde e Secretaria Municipal de Saúde, Manaus, Amazonas, Brasil \\ 2. Universidade de Brasília, Faculdade de Medicina, Laboratorio de Técnicas Histológicas, Distrito Federal, Brasil \\ 3. Universidade de Brasilia, Faculdade de Medicina, Laboratório de Imunologia Celular, Distrito Federal, Brasil \\ 4. Universidade de Brasillia, Faculdade de Odontologia, Distrito Federal, Brasil \\ 5. Universidade de Brasília, Faculdade de Odontologia, Departamento de Endodontia, Distrito Federal, Brasil \\ 6. Universidade de Brasília, Faculdade de Odontologia, Departamento de Periodontia, Distrito Federal, Brasil
}

\begin{abstract}
Phagocytic functions by neutrophils/monocytes and biochemical parameters were assessed in peripheral blood of patients with periodontitis, whether or not associated to type 2 diabetes, or patients with type 2 diabetes, or systemically healthy people. Fifty-eight participants were divided into four groups: Control - systemically and periodontally healthy patients $(C, n=16)$, Periodontitis (P, $n=14)$, Type 2 Diabetes (DM, $n=11)$ and Periodontitis associated with type 2 diabetes (DMP, $n=17)$. Blood samples were used to analyze phagocytic activity and the production of superoxide anion using optical microscopy. Significantly lower phagocytic activity of neutrophils was observed in non-opsonized samples ( $p=0.008$, KruskalWallis) of the periodontitis group and in opsonized samples ( $p$ $=0.029$, Kruskal-Wallis) of the periodontitis associated with type 2 diabetes group when these groups were compared to the healthy individuals when a 20:1 yeast: phagocyte stimulus was used. Periodontitis patients, whether associated ( $p=$ 0.0007, sensitized; Kruskal-Wallis, 20:1) or not with diabetes ( $p=0.018$ and 0.0007, in the proportions 5:1 and 20:1 yeast:
\end{abstract}

monocyte respectively in sensitized samples; Kruskal-Wallis) also showed lower phagocytic function of monocytes compared to the control group. There was no significant difference in the production of superoxide anion among the evaluated groups. Severe clinical attachment loss was associated with lower levels of HDL in periodontitis patients and a higher percentage of AlC in diabetes with periodontitis patients $(p<0.05$; Pearson and Spearman correlations, respectively). Patients with both associated diseases had higher levels of triglycerides and CRP $(p<0.001$, Kruskal-Wallis) compared to patients with diabetes only. The results of the present study suggest that periodontitis negatively interferes with the innate immune response and may represent a major risk of systemic complications such as cardiovascular disease in diabetic patients or even in healthy individuals.

Received: April 2020; Accepted: November 2020.

Keywords: leukocytes - phagocytosis - superoxide anion biochemical markers -periodontitis - diabetes mellitus.

\section{Atividade fagocítica de monócitos e neutrófilos em pacientes com periodontite, associada ou não ao diabetes tipo 2}

\begin{abstract}
RESUMO
As funções fagocíticas de neutrófilos/monócitos e parâmetros bioquímicos foram avaliados no sangue periférico de pacientes com periodontite com ou sem diabetes do tipo 2, ou em pacientes com diabetes tipo 2, ou em pessoas saudáveis sistemicamente. 58 participantes foram divididos em quatro grupos: Controle - pacientes sistemicamente e periodontalmente saudáveis $(C$, $n=16)$, Periodontite ( $P, n=14)$, Diabetes Tipo 2 (DM, $n=$ 11) e Periodontite associada a diabetes tipo 2 (DMP, $n=17)$. Amostras de sangue foram usadas para analisar a atividade fagocítica e a produção de ânion superóxido por microscopia óptica. Observou-se menor atividadefagocitica dos neutrófilos em amostras não opsonizadas ( $p=0,008$, Kruskal-Wallis) do grupo periodontite e em amostras opsonizadas ( $p=0,029$, Kruskal-Wallis) do grupo periodontite associada ao diabetes
\end{abstract}

tipo 2 quando esses grupos foram comparados aos indivíduos saudáveis sob um estímulo de levedura:monócito de 20:1. Pacientes com periodontite associada ( $p=0,0007$, sensibilizados; Kruskal-Wallis, 20: 1) ou não com diabetes ( $p=$ 0,018 e 0,0007, nas proporções 5: 1 e 20: 1 delevedura: monócito, respectivamente, em amostras sensibilizadas; Kruskal- Wallis) também demonstraram menor função fagocítica dos monócitos em comparação com o grupo controle. Não houve diferença significativa na produção de ânion superóxido entre os grupos avaliados. A perda de inserção clínica grave foi associada a níveis mais baixos de HDL na periodontite e maior percentual de AlC nos pacientes com periodontite associada ao diabetes ( $p<0,05$; correlações de Person e Spearman, respectivamente). Os pacientes com ambas as doenças associadas apresentaram 
níveis mais altos de triglicerídeos e PCR $(p<0,001$, KruskalWallis) em comparação aos pacientes com somente diabetes. Os resultados do presente estudo sugerem que a periodontite interfere negativamente na resposta imune inata $e$ pode representar um risco maior para complicações sistêmicas,

\section{INTRODUCTION}

Phagocytosis is performed by the host's phagocytic cells to eliminate invading microorganisms and stimulate other immune responses. Phagocytosis is initiated by the interaction of cell surface receptors with ligands found on the microorganisms, such as lipopolysaccharides, or host-derived opsonins, such as complement or IgG antibodies ${ }^{1}$.

The phagocytic cell killing response to periodontal pathogen invasion results in the formation of reactive oxygen species (ROS), such as superoxide anion, which contribute to local periodontal tissue destruction when released in larger amounts ${ }^{2}$.

During periodontitis, ROS end-metabolites can be translocated to distant organs via blood circulation, leading to tissue damage ${ }^{3}$.

It is currently clear that periodontitis is associated with some systemic diseases such as diabetes mellitus $(\mathrm{DM})^{4}$. Diabetic patients with inadequate glycemic control are more likely to develop severe periodontitis. Emerging evidence also indicates that the severity of periodontitis is related to higher mortality rates and significantly correlates with dyslipidemia, oxidative stress $^{3}$ and cardio-renal complications of diabetes ${ }^{4}$.

Considering the infectious and inflammatory nature of periodontal diseases, the aim of this study was to analyze the influence of periodontitis alone or in association with type 2 diabetes on the phagocytic functions of monocytes and neutrophils and on the biochemical parameters of peripheral blood.

\section{MATERIALS AND METHODS}

\section{Study groups}

The study protocols, procedures and consent form were approved by the Human Research Ethics Committee, University of Brasília (UnB) (process number 46609515.7.0000.0030), in accordance with Brazilian legislation, which complies with the Declaration of Helsinki, as revised in 2013. All participants were individually informed about the como a doença cardiovascular, em pacientes com diabetes ou mesmo em indivíduos saudáveis.

Palavras-chave: leucócitos - fagocitose - ânion superóxido marcadores bioquímicos - periodontite - diabetes mellitus.

study and agreed to participate by signing a written informed consent form.

Fifty-eight non-smokers (23 males and 35 females), $\geq 30$ years old, were included in the study, which was further divided into four groups: periodontitis group (P), type 2 Diabetes Mellitus group (DM), periodontitis and type 2 DM group (DMP) and Controls (C). They were recruited from the Periodontology Clinic at the University Hospital of Brasília (HUB), Distrito Federal, Brazil.

Participants were interviewed to obtain medical and demographic information, including age, sex and tobacco use.

An experienced examiner (PFN) conducted the periodontal clinical examination, which consisted of six sites recorded for each tooth, excluding third molars, measured using a periodontal probe (UNC 15 screening probe). The following parameters were recorded: probing depth (PD), clinical attachment loss (CAL), visible plaque index (PI) and gingival bleeding on probing (BOP) index.

The calibration and measurements of periodontal clinical parameters were repeated within 24 hours, showing agreement of over $80 \%$. BOP was calculated by the Kappa coefficients, and intraexaminer agreement was $>0.85$.

The periodontitis group (P) consisted of subjects without systemic diseases and with at least 12 teeth. The following inclusion criteria were adopted: clinical diagnosis of periodontitis at $\geq 2$ non-adjacent teeth (CAL $\geq 3 \mathrm{~mm}, P D \geq 4 \mathrm{~mm}, \geq$ stage II; grade A). The diabetes mellitus with periodontitis group (DMP) consisted of individuals previously diagnosed with type $2 \mathrm{DM}$ with diagnosis of periodontitis. The same criteria as for the periodontitis group were used, with the inclusion of grades $\mathrm{B}$ or $\mathrm{C}$ periodontal conditions. Both controlled (A1c $<7 \%$ ) and uncontrolled diabetic patients (A1c $\geq 7 \%$ ) were included.

The diabetes group (DM), consisted of subjects with previous diagnosis of type 2 diabetes, regardless of glycemic control status, without periodontal disease and who had at least 12 teeth. 
The control group (C) consisted of orally and systemically healthy individuals, with at least 20 teeth. The periodontal health criteria used for both $\mathrm{DM}$ and $\mathrm{C}$ groups were the absence of interproximal or buccal CAL $\geq 3 \mathrm{~mm}, \mathrm{PD} \leq 3 \mathrm{~mm}, \mathrm{BOP}<10 \%$ and no radiographic evidence of bone loss.

The following exclusion criteria were adopted: anyone who smoked within the past 5 years, periodontal treatment within the last 12 months, antimicrobial therapy for systemic conditions or topical oral use within the last 12 months, use of medications such as anti-inflammatory, corticoid and immunosuppressive therapy; pregnant or lactating women; autoimmune, infectious, allergic, renal and gastrointestinal diseases; cancer; morbid obesity [body mass index $(\mathrm{BMI})>40 \mathrm{~kg} / \mathrm{m}^{2}$ ] or malnutrition $\left(\mathrm{BMI}<18.5 \mathrm{~kg} / \mathrm{m}^{2}\right)^{5}$.

Periodontal disease was classified according to the new classification of periodontal diseases and conditions ${ }^{6}$.

\section{Blood sampling for biochemical analysis}

Blood samples were taken after eight hours' fasting. Samples were collected and analyzed at Laboratory Sabin, Brasilia - Distrito Federal, Brazil. The following parameters were evaluated: Hemogram, lipid profile, fasting glycemia, glycated hemoglobin (A1c) and C-reactive protein. (CRP).

\section{Evaluation of phagocytosis}

A technique previously described ${ }^{7}$ was adapted to assess phagocytosis of dead Saccharomyces cerevisiae via pattern-recognition receptors or facilitated by opsonins.

Whole blood ( $40 \mu \mathrm{L} /$ area) was placed on clean glass slides containing eight marked areas $7 \mathrm{~mm}$ in diameter each and incubated in a wet chamber for 45 minutes at $37^{\circ} \mathrm{C}$. The slides were then rinsed with $0.15 \mathrm{M}$ PBS, $\mathrm{pH} 7.2$ at $37^{\circ} \mathrm{C}$, to remove non-adherent cells. After washing, monocytes and neutrophils remained adhered to the slide approximately in the same proportion as they were in the whole blood. Adherent cells were incubated with a suspension $0.625 \times 10^{5}$ or $2.5 \times 10^{5}$ S. cerevisiae in $20 \mu \mathrm{L}$ Hankstris(Sigma, USA), pH 7.2, with 10\% heat-inactivated fetal calf serum (FCS) (Gibco) for $30 \mathrm{~min}$ in a wet chamber at $37^{\circ} \mathrm{C}$. Slides were then rinsed with $0.15 \mathrm{M}$ PBS at $37^{\circ} \mathrm{C}$ to eliminate non-phagocytosed S. cerevisiae and the final wash was done with $30 \%$ FCS in Hanks-tris. The slides were then fixed with absolute methanol and stained with $10 \%$ Giemsa solution. The number of $S$. cerevisiae phagocytosed by 200 neutrophils or monocytes in single preparations was assessed by optical microscopy. Microscopic fields distributed throughout the slide were randomly selected and all phagocytes in each particular field were examined by a single blinded examinator (ACGC). The phagocytic index was calculated as the average number of phagocytosed $S$. cerevisiae per phagocytosing neutrophil or monocyte, multiplied by the percentage of these cells engaged in phagocytosis ${ }^{7}$.

Yeasts to be phagocytosed by phagocytes were used with or without previous incubation with fresh serum from the donor for $30 \mathrm{~min}$ at $37^{\circ} \mathrm{C}$. In the former case, yeast cells were considered sensitized, because complement molecules present in serum opsonized them and phagocytosis occurred through phagocytes $\mathrm{CR} 1$ and $\mathrm{CR} 3$ receptors that bind to $\mathrm{C} 1$ and $\mathrm{C} 3$ components of complement adhered to the surface of the yeasts ${ }^{7}$. The yeast cells that were not pre-incubated with fresh serum from the donor, but were incubated with inactivated fetal bovine serum, were considered as non-opsonized, and their phagocytosis occurred via the pattern-recognition receptors (PRR) of neutrophils or monocytes ${ }^{8}$.

\section{Evaluation of superoxide anion production}

The superoxide anion production was analyzed by the Nitro blue tetrazolium (NBT) test based on an adaptation of a technique previously described ${ }^{9}$. This technique evaluates the microbicidal mechanism of phagocytes by their ability to generate toxic oxygen radicals capable of reducing the compound NBT to an insoluble form, called formazan, which can be identified under optical microscopy by a blue color in the cytoplasm of the cell.

The quantity of NBT reduced is directly proportional to the amount of oxygen radicals produced by phagocytes, and these molecules are among the principal microbicidal agents produced by phagocytic cells ${ }^{2}$.

Briefly, the phagocytes adhered to the slide, as previously described, were incubated with $0.05 \%$ NBT solution in Hanks-tris (Sigma, USA) for 20 minutes at $37^{\circ} \mathrm{C}$ in a humidified chamber.

The slides were then washed, fixed with methanol and stained with a solution of $1.4 \%$ safranin and $28.6 \%$ glycerol in distilled water. NBT reduction was also stimulated by sensitized $S$. cerevisiae. The 
percentage of phagocytes with reduced NBT in the cytoplasm was assessed by a blinded researcher (ACGC) using optical microscopy.

\section{Statistical analysis}

Sample size was determined for a desired power of $90 \%$ and an alpha level of significance of 0.05 using Sigma Stat software, based on the annual number of patients seen at the periodontal clinic (HUB). Estimated sample size was 60.

Prism ${ }^{\circledR}$ software (GraphPad, USA) was used in the data analysis. Normality of variables was previously verified by the Kolmogorov-Smirnov test. Differences among three or more groups were verified by analysis of variance (ANOVA), followed by the Turkey test or Kruskal-Wallis test, followed by Dunn's method, to variables with Gaussian or non-Gaussian distribution and similar or different variances, respectively. Pearson or Spearman correlation coefficients were used to estimate the correlation between periodontal clinical attachment loss versus hematologic parameters, for variables with Gaussian or non-Gaussian distribution, respectively. The level of significance was set at $\mathrm{p}<0.05$.

\section{RESULTS}

\section{Clinical and demographic data}

All individuals that volunteered to participate were chosen to be part of a convenience sample. A total 58 participants, $23(39.7 \%)$ males and $35(60.3 \%)$ females, were enrolled at the study.

Four groups were assessed as follows: 1) Periodontitis group (P) including 14 patients $(8 \mathrm{~F} ; 6 \mathrm{M})$, age $45 \pm 9$; 2) Diabetes type 2 with periodontitis group (DMP) including 17 patients, age 53 \pm 7, 7 females (F) and 10 males (M); 3) Diabetes type 2 group (DM), without periodontal diseases, including 11 patients $(9 \mathrm{~F}$; $2 \mathrm{M})$, age $51 \pm 10$; 4) Control group (C) including 16 healthy volunteers $(11 \mathrm{~F} ; 5 \mathrm{M})$, age $42 \pm 9$.

The control group had a significantly higher number of teeth (mean 26.6; $\mathrm{p}=0.0108$; Kruskal-Wallis followed by Dunn's comparison) in relation to patients with diabetes (mean 21.6 or 21.3 , with or without periodontitis) or periodontitis (mean 22.8), but without significance.

Mean body mass index (BMI) of DM $\left(31 \mathrm{~kg} / \mathrm{m}^{2}\right)$ and DMP patients $\left(30 \mathrm{~kg} / \mathrm{m}^{2}\right)$ was higher than the control $\left(26 \mathrm{~kg} / \mathrm{m}^{2}\right)$ or periodontitis group $\left(28 \mathrm{~kg} / \mathrm{m}^{2}\right.$ $p=0.0137$, ANOVA).

Patients with periodontitis (with or without diabetes) had significantly higher probing depth (PD), clinical attachment loss (CAL), plaque index (PI) and bleeding on probing (BOP) when compared to groups without periodontal disease $(\mathrm{p}<0.0001$; Kruskal-Wallis) (Table 1).

\section{Laboratory parameters}

All values obtained from the hematological examinations were within the normality or reference values, except for the glycemic indices for both diabetes groups or triglycerides in the DMP group. Although triglyceride values in subjects with diabetes were within normal ranges, this was not observed in subjects with diabetes associated with periodontitis, whose concentrations were above established standards (Table 2).

Correlation analysis showed that there was a moderate inverse correlation between $\mathrm{CAL}$ and HDL $(r=-0.5870$, Pearson $)$ in periodontitis patients (Fig. 1) and a moderate positive correlation between CAL and A1C in DMP patients $(\mathrm{r}=0.6618$, Spearman, Fig. 2). No more significant correlations were found between CAL and the other hematologic parameters in periodontitis patients (with or without diabetes) (Table 3).

\section{C-reactive protein (CRP) levels}

Among patients with diabetes, those with periodontitis as co-morbidity had higher and significant CRP levels (5/0.3-9.5) compared to the control group (0.3/0.02-1.4) or diabetes without periodontitis group (0.4/0.02-2.9) (Fig. 3).

\section{Phagocytic activity by neutrophils}

There was no difference in the phagocytic index among the groups, when sensitized or non-sensitized yeasts were used in the proportion 5:1 yeasts per neutrophil $(p<0.05)$. However, the number of sensitized phagocytized yeasts per neutrophil was significantly lower in periodontitis $(1.6 \pm 0.5)$ and DMP groups $(1.8 \pm 0.6)$ compared to controls (2.4 \pm 0.7$),(\mathrm{p}=0.007$, ANOVA).

When the stimulus was used in the proportion 
Table 1 - Clinical periodontal data from the participants of the study.

\begin{tabular}{|c|c|c|c|c|c|} 
& $\mathbf{C}$ & $\boldsymbol{P}$ & $\mathbf{D M}$ & $\boldsymbol{D} \mathbf{M}-\boldsymbol{P}$ & p-Value \\
\hline $\mathrm{CAL}+(\mathrm{mm})$ & $2.8 \pm 0.2$ & $6.3 \pm 1.9$ & $2.9 \pm 0.2$ & $5.5 \pm 1.6$ & $<0.0001$ \\
\hline$P D+(\mathrm{mm})$ & $2.1 \pm 0.4$ & $6.1 \pm 1.7$ & $2.4 \pm 0.3$ & $5.5 \pm 1.2$ & $<0.0001$ \\
\hline$P I(\%)$ & $12.1 \pm 2.9$ & $79 \pm 27.4$ & $13.8 \pm 1.4$ & $77 \pm 23.3$ & $<0.0001$ \\
\hline BOP $(\%)$ & $7.5 \pm 1.3$ & $48 \pm 26.1$ & $8.9 \pm 1.9$ & $38 \pm 25.8$ & $<0.0001$ \\
\hline Extension (\%) & 0 & $51 \pm 29.8$ & 0 & $42 \pm 26.3$ & $<0.0001$
\end{tabular}

Kruskal-Wallis test. ${ }^{+}$Deeper pockets or major CAL per tooth. Values are expressed as mean \pm standard deviation; $p$-value significant when $<0.05$. Legends: $\mathrm{C}=$ control group; $\mathrm{P}=$ periodontitis group; $\mathrm{DM}=$ diabetes mellitus group; $\mathrm{DMP}=$ diabetes mellitus with periodontitis group; $\mathrm{PI}=$ plaque index $\mathrm{BOP}=$ bleeding on probing; $\mathrm{CAL}=$ clinical attachment loss; $\mathrm{PD}=$ probing depth .

\section{Table 2 - Biochemical profile of individuals according to study groups.}

\begin{tabular}{|c|c|c|c|c|c|c|}
\hline \multirow{2}{*}{\multicolumn{2}{|c|}{ Groups }} & C & $\mathbf{P}$ & DM & DMP & RV \\
\hline & & \multicolumn{5}{|c|}{$($ Mean $\pm S D)$} \\
\hline \multirow{4}{*}{ Lipids } & $\begin{array}{l}\text { Total cholesterol } \\
\qquad(\mathrm{mg} / \mathrm{mL})\end{array}$ & $188 \pm 34$ & $192 \pm 35$ & $178 \pm 28$ & $195 \pm 39$ & $<190$ \\
\hline & $\begin{array}{c}\mathrm{HDL} \\
(\mathrm{mg} / \mathrm{mL})\end{array}$ & $50 \pm 10$ & $53 \pm 10$ & $47.8 \pm 10.8$ & $47 \pm 8$ & $>40$ \\
\hline & $\begin{array}{c}\text { LDL } \\
(\mathrm{mg} / \mathrm{mL})\end{array}$ & $113 \pm 31$ & $113 \pm 25$ & $95.5 \pm 24.7$ & $107 \pm 42$ & $<130$ \\
\hline & $\begin{array}{l}\text { Triglycerides } \\
\text { (mg/mL) }\end{array}$ & $124 \pm 55$ & $131 \pm 75$ & $186 \pm 150$ & $214 \pm 102$ & $<150$ \\
\hline \multirow{2}{*}{ Blood glucose } & A1c (\%) & $5 \pm 0$ & $5 \pm 0$ & $8 \pm 2^{\star \#}$ & $7 \pm 1^{* \#}$ & 4 to 6 \\
\hline & Glucose (\%) & $88 \pm 9$ & $97 \pm 12$ & $139 \pm 50^{*}$ & $138 \pm 43^{\star \#}$ & 70 to 99 \\
\hline \multirow{2}{*}{ Hemogram } & Hematocrit (\%) & $42 \pm 4$ & $69 \pm 102$ & $41 \pm 4$ & $66 \pm 94$ & $\begin{array}{l}36.0 \text { a } 54.0 \sigma^{\lambda} \\
33.0 \text { a } 47.8 \text { ㅇ }\end{array}$ \\
\hline & $\begin{array}{l}\text { Total leukocytes } \\
\qquad\left(\mathrm{mm}^{3}\right)\end{array}$ & $6359 \pm 1510$ & $6746 \pm 1942$ & $5866 \pm 1503$ & $7918 \pm 2738$ & 3600 to 11000 \\
\hline
\end{tabular}

20:1 yeasts per neutrophil, the phagocytic index in periodontitis patients $(3.5 \pm 2.4)$ was lower compared to controls (16.6 \pm 16.9$)$ and DM patients $(26.7 \pm 22.1)$, in the non-sensitized samples ( $\mathrm{p}=0.008$, KruskalWallis). These results can be related to a lower frequency of neutrophils involved with phagocytosis in the periodontitis group $(7 \pm 15.8)$ compared to the DM group (12.5 \pm 9.8$),(p=0.04$, Kruskal-Wallis).

Healthy individuals also had a higher phagocytic index $(223.5 \pm 56.1)$ when compared to patients with diabetes associated to periodontitis $(126.8 \pm 101.1)$ in the opsonized samples, in the proportion of 20 yeasts per neutrophil ( $\mathrm{p}=0.029$, Kruskal-Wallis). There was a higher number $(\mathrm{p}=0.008$, ANOVA) of phagocytized $S$. cerevisiae per neutrophil in controls $(2.9 \pm 0.7)$ compared to patients with DMP $(2 \pm 0.7)$ or periodontitis alone $(1.9 \pm 0.7)$. The results are summarized in Fig. 4.

\section{Phagocytic activity of monocytes}

There was no difference in the phagocytic index $(\mathrm{PhI})$ among the groups, when non-sensitized yeasts were used in the proportion $5: 1$ yeasts permonocyte $(p<0.05)$. However, PhI was lower in periodontitis patients (82.4 \pm 59.2$)$ compared to the controls $(132.9 \pm 27.5)$, when sensitized yeasts were used $(\mathrm{p}=0.018$, KruskalWallis). There was also a significantly lower percentage of cells engaged in phagocytosis in periodontitis (51.5 \pm 17.9$)$ and DMP (51.8 \pm 21.7$)$ groups compared to the control group (73.5 \pm 8.1$)$ in sensitized samples ( $p=0.001$, Kruskal-Wallis).

There was no significant difference in the phagocytic 


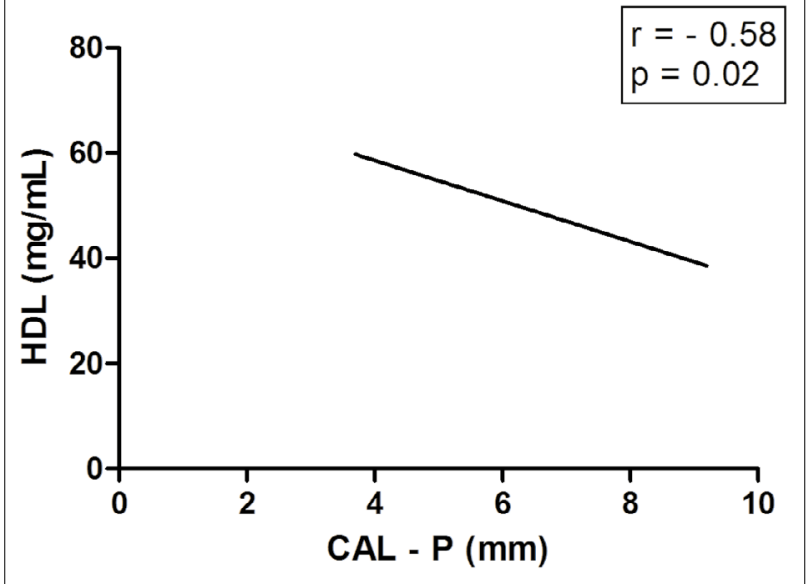

Fig. 1: Pearson correlation analysis between clinical attachment loss (CAL) and serum HDL levels during periodontitis $(P)$. $p<0.05$.

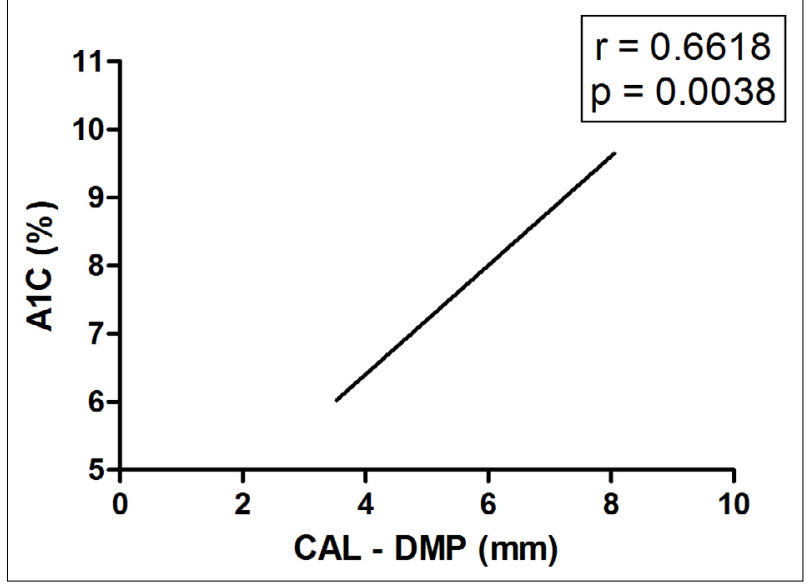

Fig. 2: Spearman correlation analysis between clinical attachment loss (CAL) and serum glycated hemoglobin (A1C) levels during periodontitis associated to diabetes (DMP). $p<0.05$.

Table 3. Correlation analysis between clinical attachment loss and biochemical parameters.

\begin{tabular}{|c|c|c|c|c|c|c|c|c|}
\hline $\mathbf{P}$ & CAL X TC & CAL X HDL & CAL X LDL & CAL XTG & CAL X BG & CAL x A1C & CAL X CRP & CAL XTL \\
\hline$r$ & $-0.00006^{+}$ & $-0.5870^{+\star *}$ & $0.1747^{+}$ & $0.06601^{\#}$ & $-0.1239^{+}$ & $0.1920^{+}$ & $0.2999^{\#}$ & $0.001375^{+}$ \\
\hline$p$ & 0.9998 & $0.0273^{*}$ & 0.5503 & 0.8226 & 0.6731 & 0.5108 & 0.3195 & 0.9963 \\
\hline DMP & CAL X TC & CAL X HDL & CAL X LDL & CAL XTG & CAL X BG & CAL X A1C & CAL X CRP & CAL XTL \\
\hline 1 & $-0.32 / 2 S$ & $-0.2458^{+}$ & $-0.2 / 62 S$ & $0.2191^{+}$ & $0.4047^{\#}$ & $0.6618^{+\star \star}$ & $0.3603^{\#}$ & $0.1043^{\#}$ \\
\hline$p$ & 0.1999 & 0.3416 & 0.2831 & 0.3982 & 0.1071 & $0.0038^{x}$ & 0.1554 & 0.6904 \\
\hline
\end{tabular}

$\mathrm{P}=$ Periodontitis patients; DMP = Diabetes with periodontitis patients; $\mathrm{CAL}=$ Clinical attachment loss; $\mathrm{TC}=$ Total cholesterol; $\mathrm{HDL}=\mathrm{High}$ density lipoproteins; $\mathrm{LDL}=$ low density lipoproteins; $\mathrm{TG}=$ Triglycerides; $\mathrm{BG}=$ Blood glucose; $\mathrm{A} 1 \mathrm{C}=$ Glycated hemoglobin; $\mathrm{CRP}=\mathrm{C}$ reactive protein; $\mathrm{TL}=\mathrm{Total}$ leukocytes. ${ }^{+}$Pearson correlation. ${ }^{*}$ Spearman correlation. ${ }^{* *}$ significant correlation. ${ }^{*} p<0.05$.

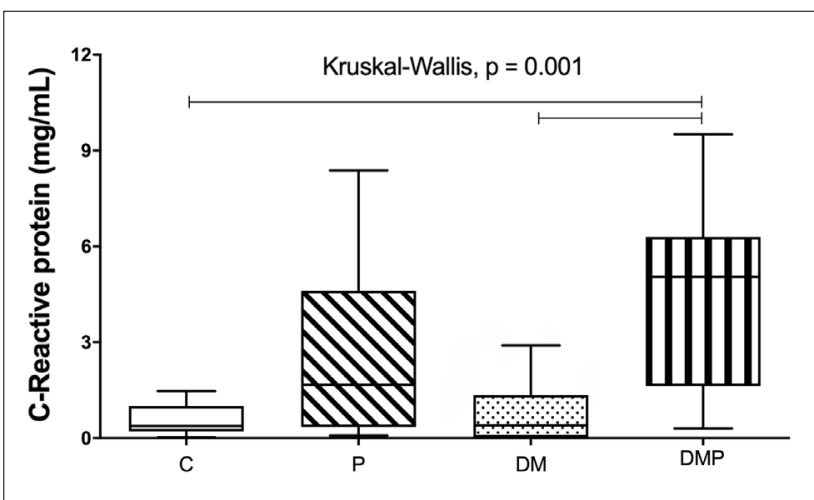

Fig. 3: CRP levels among the different study groups. KruskalWallis test. Legends: $C=$ control group; $P=$ periodontitis group; $D M=$ diabetes mellitus group; $D M P=$ diabetes mellitus with periodontitis group. $p<0.05$. Results are expressed as median with maximum and minimum quartiles.

index among groups when non-sensitized yeasts were used in the 20:1 proportion of yeasts per monocyte $(\mathrm{p}<0.05)$. A lower PhI was found in both periodontitis and DMP groups compared to controls only when sensitized yeast was used $(\mathrm{p}=0.0007$, Kruskal-Wallis).

There was a significantly lower percentage of monocyte cells engaged in phagocytosis in DMP $(52.4 \pm 23.9)$ and periodontitis groups $(53.6 \pm 15.4)$ when the 20:1 proportion of yeasts per monocyte was used ( $\mathrm{p}=0.0001$, Kruskal-Wallis). The mean number of phagocytized yeasts from the periodontitis group was lower $(1.7 \pm 0.4)$ than the controls $(2.4 \pm 0.7)(\mathrm{p}=0.02$, ANOVA). All results concerning phagocytosis by monocytes are summarized in Fig. 5.

\section{Superoxide radical}

Neither periodontal disease nor diabetes influenced the capacity of basal or stimulated production of superoxide when compared to the control or diabetes groups, as shown in Fig. 6. 


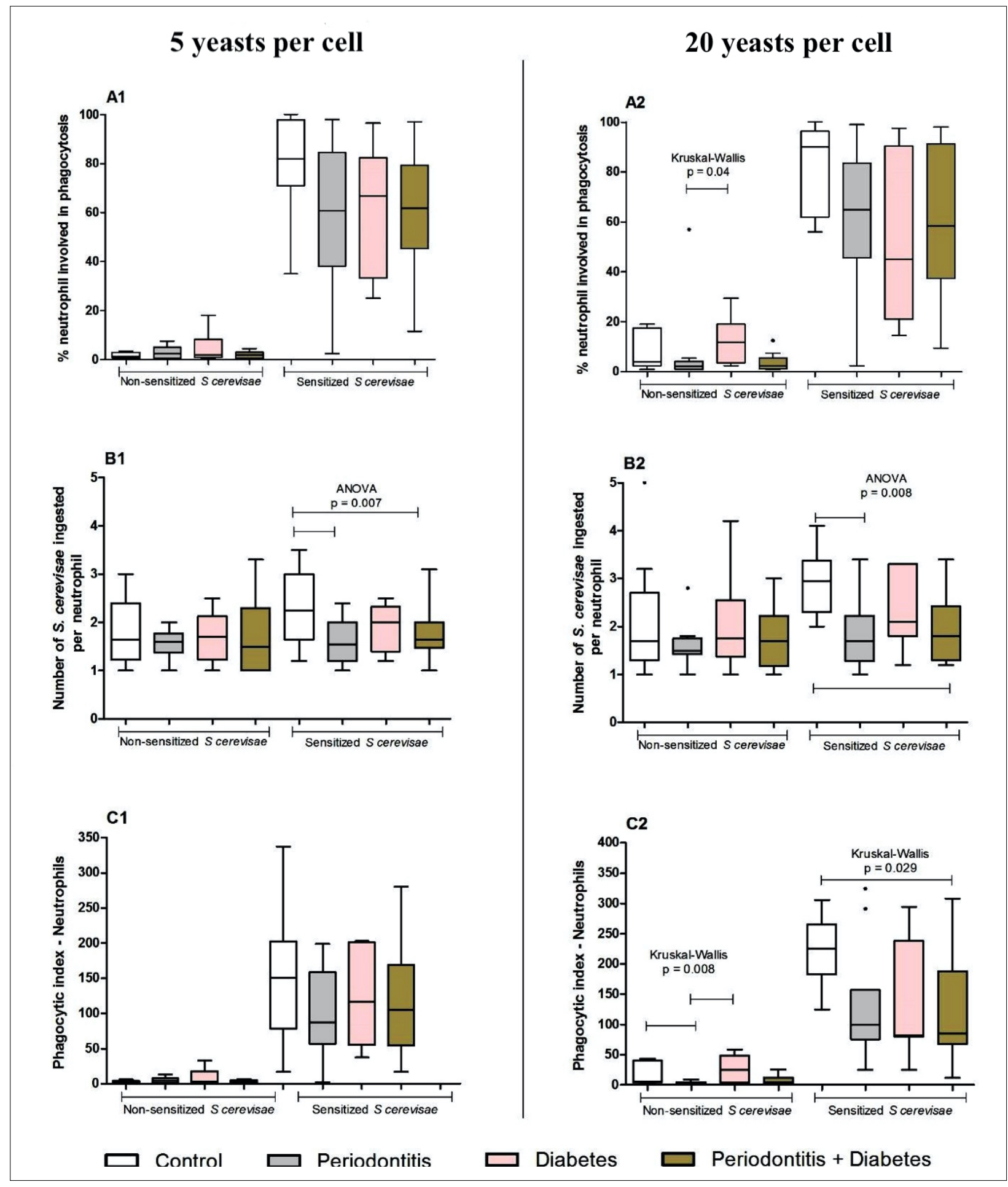

Fig. 4: Phagocytic capacity of neutrophils obtained from the peripheral blood of individuals in the control (C, n.16), periodontitis $(P, n .14)$, diabetes $(D M, n .11)$ and periodontitis + diabetes (DMP, n.17) groups evaluated by the phagocytic index (C1 and C2), which is the product of percentage of cells involved in phagocytosis (A1 and A2) by mean yeasts (sensitized or not with the individual's own serum) ingested per cell (B1 and B2). The medians, quartiles, maximum and minimum values are shown from a single experiment, representative of six independent experiments (three with 5 yeasts and three with 20 yeasts per cell, from 58 samples). The experiments were performed in duplicate. ANOVA or Kruskal-Wallis were performed according to the indication in the figure. $p<0.05$. 


\section{5 yeasts per cell}
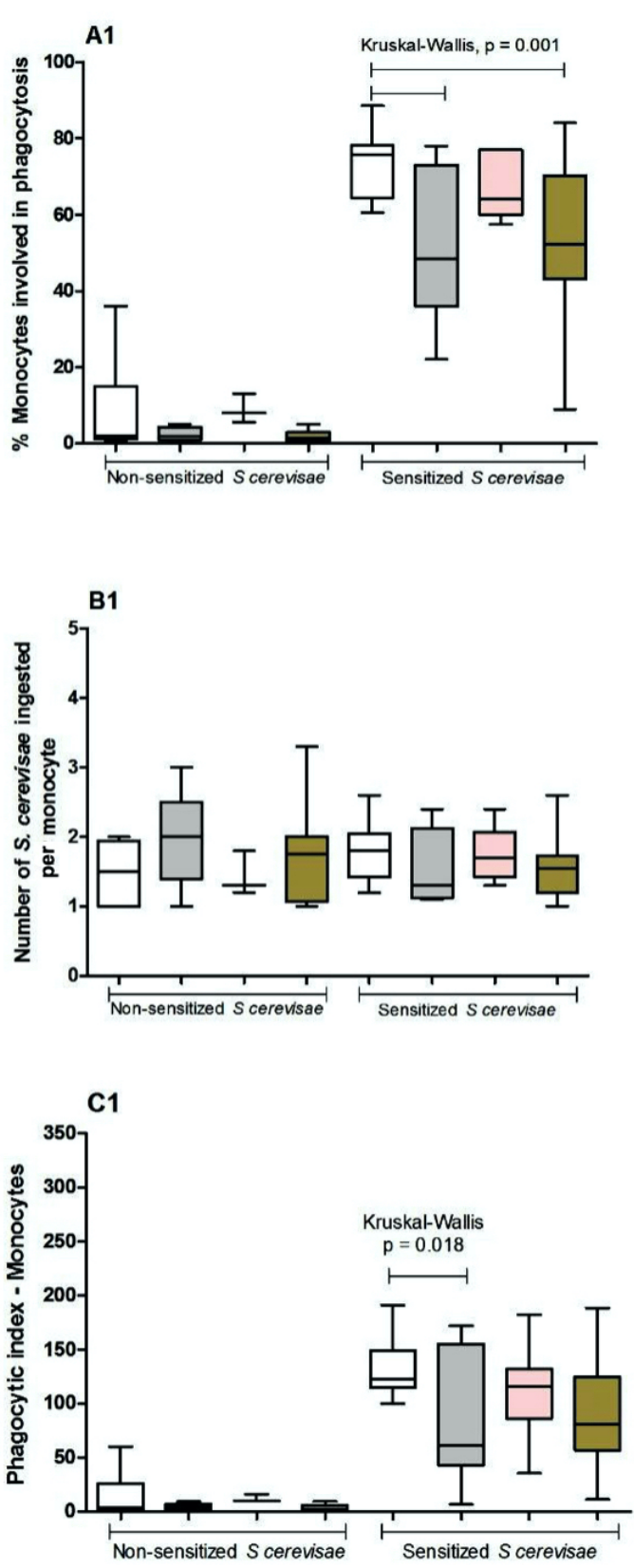

\section{0 yeasts per cell}
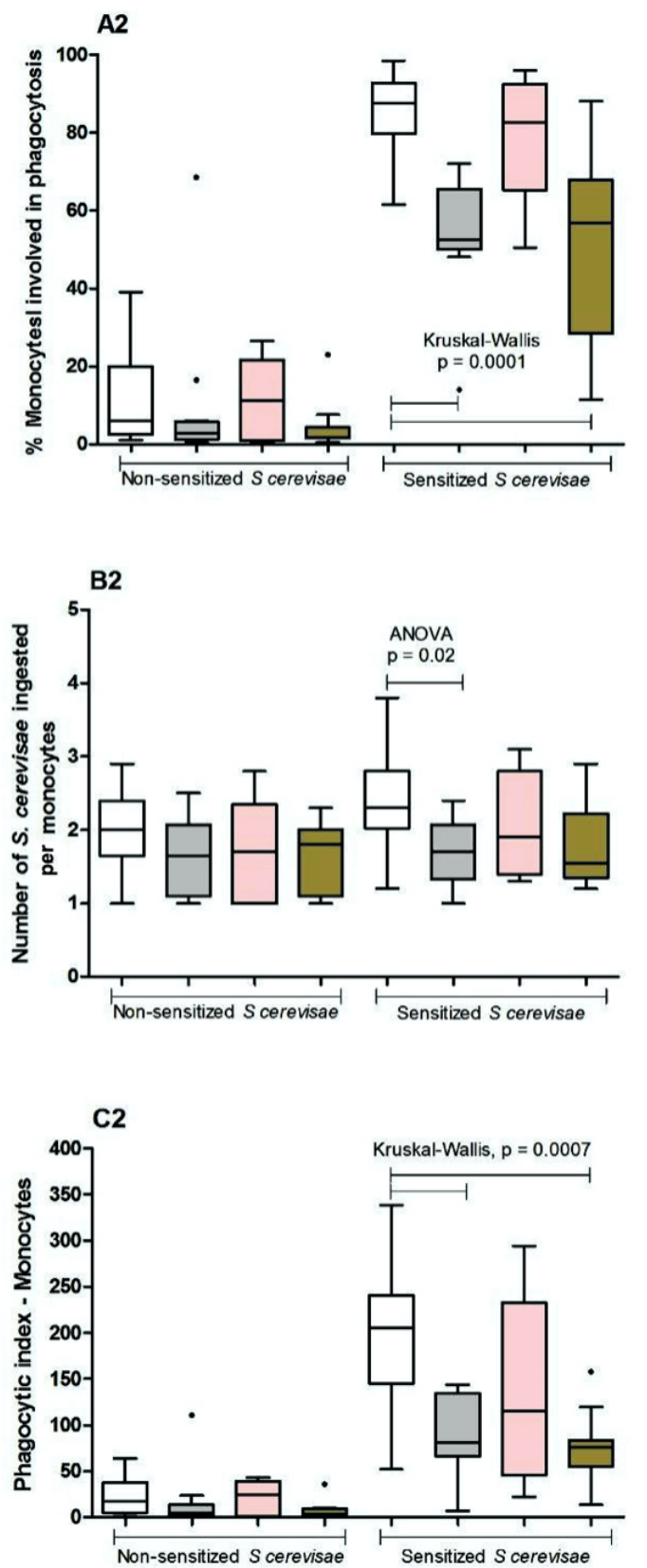

Control $\square$ Periodontitis

Diabetes

Periodontitis + Diabetes

Fig. 5: Phagocytic capacity of monocytes obtained from the peripheral blood of individuals in the control (C, n.16), periodontitis $(P, n .14)$, diabetes $(D M, n .11)$ and periodontitis + diabetes (DMP, n.17) groups evaluated by the phagocytic index (C1 and C2), which is the product of percentage of cells involved in phagocytosis (A1 and A2) by mean yeasts (sensitized or not with the individual's own serum) ingested per cell (B1 and B2). The medians, quartiles, maximum and minimum values are shown from a single experiment, representative of six independent experiments (three with 5 yeasts and three with 20 yeasts per cell, from 58 samples). The experiments were performed in duplicate. ANOVA or Kruskal-Wallis were performed according to the indication in the figure. $p<0.05$. 


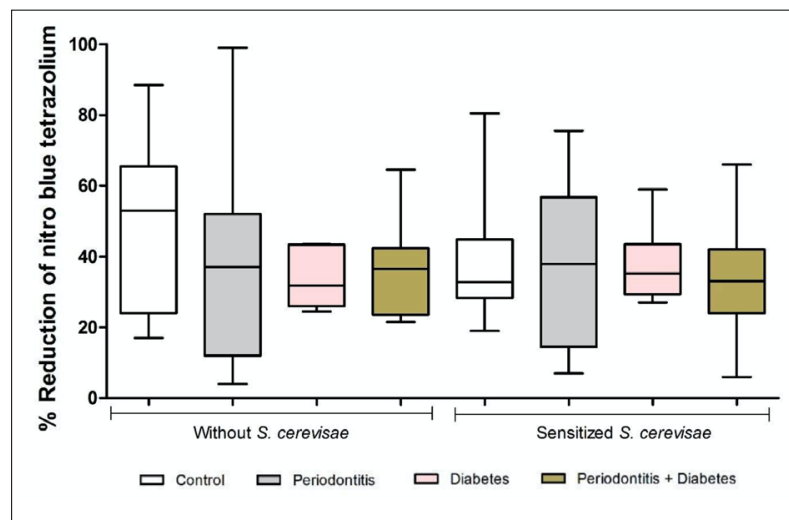

Fig. 6: Percentage of reduction of NBT (nitro blue tetrazolium) test by peripheral blood leukocytes from individuals in the control $(C, n .16)$, periodontitis $(P, n .14)$, diabetes $(D M, n .11)$ and periodontitis + diabetes (DMP, n.17) groups. The results showed that both basal (Kruskal-Wallis test) and S. cerevisiae-stimulated (ANOVA) production did not differ between groups. The medians, quartiles and extreme values are shown from a single experiment, representative of two independent experiments, from 58 samples. The experiments were performed in duplicate. $p<0.05$.

\section{DISCUSSION}

This study analyzed the association between periodontitis and diabetes, since to date, the mechanisms by which periodontitis promotes metabolic dysfunction are not fully understood.

Regarding the clinical characteristics of the study population, healthy individuals were found to have more teeth than periodontitis and diabetes patients with or without periodontitis. This probably reflects the fact that general healthcare is, in addition to other factors, associated with oral healthcare, since both DM2 and periodontitis are often associated with risk factors such as health-threatening habits and lifestyle ${ }^{1-4,6}$.

The patients in our study mainly presented stage III periodontitis, grade A, with severe, generalized extension of the disease (reaching more than $30 \%$ of the teeth present on the oral cavity).

The total surface area of this periodontal inflammatory field is estimated to be the size of the palm of the hand. Immediate medical intervention would be necessary if there were a lesion like this on the skin. However, periodontitis is frequently ignored by health professionals, even though it may be associated with a range of systemic diseases and conditions ${ }^{10}$.

Systemically healthy subjects, including those with periodontitis, had a maximum body mass index (BMI) of $28 \mathrm{~kg} / \mathrm{m}^{2}$, while the groups with diabetes had BMI higher than $30 \mathrm{~kg} / \mathrm{m}^{2}$. This indicates that most of the participants were already overweight or in class 1 obesity according to the World Health Organization $^{5}$. It is worth mentioning that BMI between 17 and $25 \mathrm{~kg} / \mathrm{m}^{2}$ provides a better survival rate and that the relative risk of mortality increases in individuals outside this range ${ }^{5}$.

Although we did not find differences in the hemogram and the leukogram parameters among all categories of patients and controls, other studies have reported increased levels of total leukocyte counts ${ }^{11}$, in contrast to our results regarding patients with periodontitis, and lower levels of erythrocytes and hemoglobin in severe chronic periodontitis patients compared to controls ${ }^{12}$.

Interestingly, we found that the higher the clinical attachment loss, the lower was the HDL level detected in patients with periodontitis. This suggests that severity of periodontitis could indirectly be an important risk factor for cardiovascular disease by influence of blood lipid concentrations such as lower levels of HDL.

The lower HDL levels in circulation during periodontitis might be due to the fact that local chronic inflammation leads to the release of LPS by Gram-negative bacteria and cytokines as IL- $1 \beta$ and TNF- $\alpha$ in blood stream, which have the capacity to influence lipid metabolism ${ }^{13}$. Furthermore, low HDL levels may also indirectly contribute to inflammatory processes because HDL has antiinflammatory properties and can decrease the adhesivity of endothelial cells ${ }^{13}$.

In contrast to participants with DM who had triglyceride levels similar to controls, those with DMP presented higher levels of triglycerides when compared to healthy individuals, even exceeding reference values. This may be an indication that periodontal disease is capable of predisposing patients with DM to a higher risk of complications such as the development of cardiovascular diseases, since the literature reports a positive association between high levels of triglycerides and higher cardiac risk ${ }^{14}$.

Periodontitis has been associated with a more reduced glycemic control in diabetes ${ }^{10}$. Nevertheless, our study did not find differences between subjects with DMP and DM alone concerning the glycemic levels (blood glucose or \% A1c). However, after performing the correlation analysis, we found that the higher the clinical attachment loss, the 
higher was the A1C level in patients with diabetes associated to periodontitis.

A cohort longitudinal study in Germany ${ }^{15}$ conducted over 15 years in patients with severe periodontitis showed that A1c levels, just after five years from their baseline levels, were significantly higher than in healthy individuals. Additionally, after a 10-year follow-up period ${ }^{16}$, another study reported a greater increase in the prevalence of periodontal disease among patients who developed glucose intolerance than among those who had not. This poorer control in glycemic indices increases the risk for the incidence of diabetes in non-diabetic patients, insulin resistance in patients with DM and disease complications, including mortality ${ }^{17}$.

Regarding innate immune defense, leukocytes are the body's main mechanism against microbial invasion. At the beginning of a bacterial infection, neutrophils are the predominant cells involved in host defense, and they also play an important role in the course of pathogenesis and inflammation due to infectious diseases ${ }^{18}$. Leukocytes respond to virulence factors with the secretion of pro-inflammatory mediators such as cytokines, chemokines, reactive oxygen species (ROS) and C-reactive protein (CRP) ${ }^{19}$. CRP is mainly produced by the liver, and cardiovascular disease has $\mathrm{CRP}$ as an independent predictor of its occurrence ${ }^{20}$. The present study found no significant differences in leukocyte counts between periodontitis patients and controls; however, other studies have reported different results ${ }^{21,22}$. Patients with periodontitis may present a significantly higher number of leukocytes compared to healthy people, which may indicate an increased risk of myocardial infection ${ }^{21}$. A study conducted by Pejčić et al. ${ }^{22}$ concluded that an increase in total leukocyte count in patients with periodontitis, especially in its severe form, may be an indicator of possible exposure to a systemic disease, and may represent an important warning for physicians to refer their patients to a dentist.

Phagocytes, such as neutrophils and monocytes, stand out as leukocytes that act in the initial defense response against periodontal pathogens. Notwithstanding, Carneiro et $\mathrm{al}^{23}$ observed a significant reduction of phagocyte functions in individuals with periodontitis. In other studies, authors reported that non-surgical periodontal treatment significantly improved the clinical periodontal status of subjects with periodontal disease and resulted in significantly increased phagocytosis of neutrophils ${ }^{24}$ and monocytes ${ }^{25}$ to levels observed in control subjects.

The elevated number of white blood cells has been associated with the risk of coronary heart disease, cardiovascular disease, atherosclerosis, thrombosis and myocardial ischemia. In this context, the inflammatory nature of chronic infections such as periodontitis could be associated with leukocytosis and major CRP levels in the bloodstream ${ }^{26}$.

CRP has been considered an independent inflammatory biomarker ${ }^{20}$ Elevated or even moderate levels of CRP can predict future vascular events and are associated with an increased risk of cardiovascular diseases such as heart strokes and myocardial infarctions among apparently healthy people with acceptable levels of $\mathrm{LDL}^{27,28}$.

Other previous studies have shown that serum inflammatory biomarkers, such as leukocytes and CRP, are elevated in diabetes ${ }^{28}$ and periodontitis patients $^{29}$. When periodontitis is associated with diabetes, these levels are further elevated ${ }^{28}$.

In line with these findings, our study showed that serum CRP levels increased when diabetes was associated with periodontitis compared to DM alone. The risk of coronary heart disease is estimated to be 1.5- to 2-fold higher in people with periodontitis than in those without the disease ${ }^{30}$.

However, our results did not show any difference in CRP levels between periodontitis patients and healthy subjects. This agrees with other studies ${ }^{31}$ that also found no difference in CRP between controls and periodontitis patients.

Acute phase proteins and leukocytosis are induced by pro-inflammatory cytokines or bacterial components released into the circulation. Probably in response to endotoxins such as lipopolysaccharides found in periodontal microorganisms, there is an increase in the production of proinflammatory cytokines that can alter lipid metabolism and insulin resistance ${ }^{32}$.

However, the current knowledge about the association between the two diseases shows that CRP serum levels decrease with the administration of mechanical periodontal treatment in periodontal disease ${ }^{33}$, supporting the view that severe periodontitis induces systemic micro-inflamation.

Concerning phagocytic function, the present study showed that when the antigen is in a low proportion (5:1) in relation to neutrophil cells, there is no difference in phagocytosis between patient groups or healthy individuals. 
The increase in the stimulus (5 to 20 yeasts per neutrophil) causes the reduction in cell phagocytic capacity when phagocytosis is mediated by cell surface receptors, in individuals with periodontitis in relation to the controls. In the same conditions, when phagocytosis is facilitated by opsonins, there is a reduction in the phagocytic activity when diabetes is associated with periodontitis compared to controls.

This impairment in neutrophil phagocytic activity seems to be related to the reduction in the number of phagocytized yeasts by neutrophils and not to the total percentage of neutrophils involved in phagocytosis.

In contrast, in monocytes, there was a reduction in phagocytic activity even when the antigen was used in a low proportion $(5: 1)$, when periodontitis group was compared to the controls. However, this reduction was only observed when phagocytosis occurred by opsonin receptors.

When an increased stimulus per monocyte $(20: 1)$ was used, there was a reduction in their phagocytic capacity, both in the periodontitis group and in diabetes associated to periodontitis group in relation to the controls, only when this function occurred by opsonins.

This impairment in monocyte phagocytic activity appears to be related to the reduction both in the number of neutrophil-phagocytized yeasts and in the frequency of cells involved in phagocytosis.

There are few studies that have analyzed the phagocytic activity of neutrophils or monocytes from the peripheral circulation. These studies report contradictory results, with reduction ${ }^{23}$ or even increase ${ }^{34}$ of this function in individuals with periodontitis. Our findings agree with those of Carneiro et al. ${ }^{23}$, who showed a deficiency in this function in individuals with severe periodontitis, indicating that periodontal disease may modify immune responses such as phagocytic activities, even in systemic healthy individuals.

Periodontitis might -by mechanisms not yet elucidated-promote opsonic defects and impair the phagocytic activity of neutrophils and, especially, of monocytes. These data may reinforce the notion that periodontitis, per se, is capable of impairing innate defense mechanisms, which could contribute to the development of diabetic complications

The superoxide anion (O2-) has been identified as one of the most important phagocyte-derived oxidants associated with periodontitis ${ }^{35}$. Neutrophils and monocytes are examples of cells that produce superoxide anions against bacterial agents ${ }^{9}$. The present study did not find any alteration in the production of superoxide among all groups. However, there is no consensus among studies that have evaluated reactive oxygen species, including superoxide, in the systemic circulation of individuals with periodontitis. Although one study found similar results ${ }^{36}$, others reported enhanced ${ }^{37}$ production of superoxide anions. The production of ROS by phagocytic cells is enhanced in periodontal pockets $^{37}$. Excessive local ROS can affect the oxidative status of tissues, activating and sustaining phagocytes to kill phagocytized pathogens. This may be harmful not only to the microorganisms but also to the host cells ${ }^{38}$.

It is important to emphasize that ROS is one of the factors that may have an impact on insulin resistance, based on two aspects. One is the association of obesity and diabetes with markers of oxidative stress $^{39}$ and the other could be related to the evidence that direct treatment with agents that induce ROS accumulation can induce insulin resistance ${ }^{40}$.

This study showed that periodontitis may change some biochemical parameters from peripheral blood, when associated or not with diabetes and, consequently, it might impair general health, contributing to the development of systemic complications in individuals with pre-diagnosed type 2 diabetes or even increasing the risk of acquired diseases such as cardiovascular disease in healthy individuals.

The reduction of phagocytosis found in the present study in patients with periodontitis, whether or not associated to diabetes, reinforces the theory that periodontitis may predispose healthy individuals to a series of systemic complications.

A possible limitation of this study is the extrapolation of an in vitro laboratory finding to a clinical condition that involves a multiplicity of interplaying functional factors. Despite this limitation, our findings reinforce the concept that periodontitis may promote significant immunological changes in cells from human peripheral blood, whose impact on the systemic condition of patients with or without diabetes mellitus, needs to be better understood. 


\section{ACKNOWLEDGMENTS}

The authors acknowledge Izabella Gontijo and Wallace Cavalcante for technical assistance in the laboratory experiments. The authors also acknowledge the National Council of Scientific and Technological Development (CNPQ) and the Federal District Research Support Foundation (FAPDF) for financial support and Research Support Center of SABIN Institute for blood dosages. Priscilla Naiff was supported by Amazonas State Research Support Foundation (FAPEAM).

\section{DECLARATION OF CONFLICTING INTERESTS}

The authors declared no potential conflicts of interest with respect to the research, authorship, and/or publication of this article.

\section{REFERENCES}

1. Lenzo JC, O'Brien-Simpson NM, Cecil J, Holden JA, Reynolds EC. Determination of active phagocytosis of unopsonized Porphyromonas gingivalis by macrophages and neutrophils using the pH-sensitive fluorescent dye pHrodo. Infect Immunol 2016;84:1753-1760.

2. Dennison DK, Van Dyke TE. The acute inflammatory response and the role of phagocytic cells in periodontal health and disease. Periodontol 2000 1997;14: 54-78.

3. França LFC, Vasconcelos ACCG, da Silva FRP, Alves EHP et al. Periodontitis changes renal structures by oxidative stress and lipid peroxidation. J Clin Periodontol 2017;44:568-576.

4. Sanz M, Ceriello A, Buysschaert M, Chapple I et al. Scientific evidence on the links between periodontal diseases and diabetes: consensus report and guidelines of the joint workshop on periodontal diseases and diabetes by the International Diabetes Federation and the European Federation of Periodontology. Diabetes Res Clin Prac 2018;137: 231-241

5. National Institutes of Health. Clinical Guidelines on the Identification, Evaluation, and Treatment of Overweight and Obesity in Adults--The Evidence Report. Obes res 1998;6:51S-209S.

6. Papapanou PN, Sanz M, Buduneli N, Dietrich T et al. Periodontitis: Consensus report of Workgroup 2 of the 2017 World Workshop on the Classification of Periodontal and Peri-Implant Diseases and Conditions. J Periodontol 2018;89:S173-S182.

7. Muniz-Junqueira MI, Peçanha LM, Silva-Filho VL, Cardoso MCA, Tosta CE. Novel microtechnique for assessment of postnatal maturation of the phagocytic function of neutrophils and monocytes. Clin Diagn Lab Immunol 2003;10:1096-102.

8. Brown GD. Innate antifungal immunity: the key role of phagocytes. Ann Rev Immunol 2011;29:1-21.

9. Muniz-Junqueira MI, de Paula-Coelho VN. Meglumine antimonate directly increases phagocytosis, superoxide anion and TNF-alpha production, but only via TNF-alpha it indirectly increases nitric oxide production by phagocytes of healthy individuals, in vitro. Int Immunopharmacol 2008;10:1633-1638.

10. Naiff P, Carneiro V, Guimarães MC. Importance of Mechanical Periodontal Therapy in Patients with Diabetes

\section{FUNDING}

Conselho Nacional de Desenvolvimento Científico e Tecnológico Process number 422070/2016-5

Fundação de Apoio a Pesquisa do Distrito Federal Process Number 0193.001.025/2015

\section{CORRESPONDENCE}

Dr. Priscilla Farias Naiff

Av Maracanã, s/n. Policlínica Dr. José Lins, Manaus-AM, Brasil. 69047-481

pri_naiff@yahoo.com

Type 2 and Periodontitis. Int J Dent 2018;25:6924631, doi: 10.1155/2018/6924631.

11. Agnihotram G, Singh M, Pamidimarri P, Jacob L, Rani S, Sravanthi. Study of clinical parameters in chronic periodontitis. Int J Appl Biol Pharm 2010;1:1202-1208.

12. Kolte RA, Kolte AP, Deshpande NM. Assessment and comparison of anemia of chronic disease in healthy subjects and chronic periodontitis patients: A clinical and hematological study. J Indian Soc Periodontol 2014;18:183186

13. Gallin JI, Kaye D, O'Leary WM. Serum lipids in infection. N Engl J Med 1969;281:1081-1086.

14. Nordestgaard BG, Benn M, Schnohr P, Tybjaerg-Hansen A. Nonfasting triglycerides and risk of myocardial infarction, ischemic heart disease, and death in men and women. JAMA 2007;298:299-308.

15. Demmer RT, Desvarieux M, Holtfreter B, Jacobs DR Jr, Wallaschofski H, Nauck M, Kocher T. Periodontal status and $\mathrm{A} 1 \mathrm{C}$ change: longitudinal results from the study of health in Pomerania (SHIP). Diabetes Care 2010;33:10371043.

16. Saito T, Shimazaki Y, Kiyohara Y, Kato I, Kubo M, Iida M, Koga T. The severity of periodontal disease is associated with the development of glucose intolerance in nondiabetics: the Hisayama study. J Dent Res 2004;83:485490.

17. Mealey BL, Rose LF. Diabetes mellitus and inflammatory periodontal diseases. Curr Opin Endocrinol Diabetes Obes 2008;15:135-141.

18. Miyasaki KT. The neutrophil: mechanisms of controlling periodontal bacteria. J Periodontol 1991;62:761-764.

19. Ursãrescu IG, Martu-Stefanache MA, Solomon MS, Pasarin L, Boatca RM, Caruntu ID, Martu S. The assessment of Il-6 and RANKL in the association between chronic periodontitis and osteoporosis. Rev Chim 2016;67:386-389.

20. Ridker PM. Clinical application of C-reactive protein for cardiovascular disease detection and prevention. Circulation 2003;107:363-369.

21. Kweider M, Lowe GD, Murray GD, Kinane DF, McGowan DA. Dental disease, fibrinogen and white cell count; links with myocardial infarction. Scot Med J 1993;38:73-74.

22. Pejčić A, Kesić L, Pešić Z, Mirković D, Stojanović M. White blood cell count in different stages of chronic periodontitis. Acta Clin Croat 2011;50:159-167. 
23. Carneiro VM1, Bezerra AC, Guimarães Mdo C, MunizJunqueira MI. Decreased phagocytic function in neutrophils and monocytes from peripheral blood in periodontal disease. Appl Oral Sci 2012;20:503-509.

24. Carneiro VM1, Bezerra AC, Guimarães Mdo C, MunizJunqueira MI Effects of periodontal therapy on phagocytic activity of peripheral blood neutrophils - evidence for an extrinsic cellular defect. Oral Health Prev Dent 2012;10:195-203.

25. Naiff PF, Carneiro VMA, Guimarães MCM, Bezerra MCB et al. Mechanical Periodontal Therapy Recovered the Phagocytic Function of Monocytes in Periodontitis. Int $\mathbf{J}$ Dent 2020; 1-9.

26. Linden GJ, Lyons A, Scannapieco FA. Periodontal systemic associations: review of the evidence. J Clin Periodontol 2013: S8-S19.

27. De Backer G,Ambrosioni E, Borch-Johnsen K, Brotons $\mathrm{C}$ et al. European guidelines on cardiovascular disease prevention in clinical practice. Eur Heart J 2003;24:16011610 .

28. King GL. The role of inflammatory cytokines in diabetes and its complications. J Periodontol 2008;79:1527-1534.

29. Loos BG, Craandijk J, Hoek FJ, Wertheim-van Dillen PM, van der Velden U. Elevation of systemic markers related to cardiovascular diseases in the peripheral blood of periodontitis patients. J Periodontol 2000;71:1528-1534.

30. Arima H, Kubo M, Yonemoto K, Doi Y et al. Highsensitivity $\mathrm{C}$-reactive protein and coronary heart disease in a general population of Japanese: the Hisayama study. Arterioscler Thromb Vasc Biol 2008;28:1385-1391.

31. Yamazaki K, Honda T, Oda T, Ueki-Maruyama K, Nakajima T, Yoshie H, Seymour GJ. Effect of periodontal treatment on the C-reactive protein and proinflammatory cytokine levels in Japanese periodontitis patients. J Period Res 2005;40:53-58.

32. Chang P, Lim LP. Interrelationships of periodontitis and diabetes: a review of the current literature. J Dent Sci 2012; 7:272-282.

33. Iwamoto Y, Nishimura F, Soga Y, Takeuchi K, Kurihara M, Takashiba S, Murayama Y. Antimicrobial periodontal treatment decreases serum C-reactive protein, tumor necrosis factor-alpha, but not adiponectin levels in patients with chronic periodontitis. J Periodontol 2003;74:1231-1236.

34. Guentsch A, Puklo M, Preshaw PM, Glockmann E, Pfister W, Potempa J, Eick S. Neutrophils in chronic and aggressive periodontitis in interaction with Porphyromonas gingivalis and Aggregatibacter actinomycetemcomitans. J Periodontal Res 2009;44:368-377.

35. Ling MR, Chapple ILC, Matthews JB. Neutrophil superoxide release and plasma C-reactive protein levels pre- and post-periodontal therapy. J Clin Periodontol 2016;43:652-658.

36. Cavalla F, Biguetti CC, Garlet TP, Trombone APF, Garlet GP. Inflammatory Pathways of Bone Resorption in Periodontitis. In: Bostanci N., Belibasakis G. Pathogenesis of Periodontal Diseases, Gewerbestrasse, Cham, Switzerland: Springer International Publishing, 2018:59-85.

37. Dahiya P, Kamal R, Gupta R, Bhardwaj R, Chaudhary K, Kaur S. Reactive oxygen species in periodontitis. J Indian Soci Periodontol 2013;17:411-416.

38. Dunnill C, Patton T, Brennan J, Barrett J et al. Reactive oxygen species (ROS) and wound healing: the functional role of ROS and emerging ROS modulating technologies for augmentation of the healing process. Int Wound $\mathrm{J}$ 2017; 14:89-96.

39. Furukawa S, Fujita T, Shimabukuro M, Iwaki M et al. Increased oxidative stress in obesity and its impact on metabolic syndrome. J Clin Invest 2004;114:1752-1761.

40. Lin Y, Berg AH, Iyengar P, Lam TK et al. The hyperglycemiainduced inflammatory response in adipocytes: the role of reactive oxygen species. J Biol Chem 2005;280:4617-4626. 